\title{
Experimental Investigation of Laser Welding Process in Butt-Joint Configurations
}

\author{
Laurent Jacques, Abderrazak El Ouafi \\ Engineering Department, University of Quebec at Rimouski, Rimouski, Canada \\ Email: abderrazak_elouafi@uqar.ca
}

How to cite this paper: Jacques, L. and El Ouafi, A. (2017) Experimental Investigation of Laser Welding Process in Butt-Joint Configurations. World Journal of Engineering and Technology, 5, 77-89. https://doi.org/10.4236/wjet.2017.51007

Received: November 30, 2016

Accepted: February 19, 2017

Published: February 22, 2017

Copyright $\odot 2017$ by authors and Scientific Research Publishing Inc. This work is licensed under the Creative Commons Attribution International License (CC BY 4.0).

http://creativecommons.org/licenses/by/4.0/ (c) (i) Open Access

\begin{abstract}
This paper presents an experimental investigation of laser welding low carbon galvanized steel in butt-joint configurations. The experimental work is focused on the effects of various laser welding parameters on the welds quality. The investigations are based on a structured experimental design using the Taguchi method. Welding experiments are conducted using a $3 \mathrm{~kW}$ Nd:YAG laser source. The selected laser welding parameters (laser power, welding speed, laser fiber diameter, gap between sheets and sheet thickness) are combined and used to evaluate the variation of four weld quality attributes (bead width, penetration depth, underfill and hardness) and to identify the possible relationship between welding parameters and weld physical and geometrical attributes. The effects of these parameters are studied using ANOVA to find their contributions to the variation of different weld characteristics. Plots of the main effects and the interaction effects are also used to understand the influence of the welding parameters. The results reveal that all welding parameters are relevant to bead width (BDW) and depth of penetration (DOP) with a relative predominance of laser power and welding speed. The effect of laser fiber diameter on penetration depth is insignificant. Typical gap-dependent weld shapes show that a small gap results in a narrower and deeper weld. Due to the standard sheared edge, an underfill between $5 \%$ and $10 \%$ occurs for no-gap experiments. The resulting hardness values are relatively similar for all the experimental tests.
\end{abstract}

\section{Keywords}

Laser Welding, Nd:YAG, Low Carbon Galvanized Steel, Taguchi Method, Butt-Joint

\section{Introduction}

Laser welding is used in the automotive industry for welding bodies with up to 
$30 \mathrm{~m}$ of welds length per vehicle. In order to design lighter cars for reduced fuel consumption, the most recent developments use tailor-welded blank, requiring various metals types and thicknesses to be welded together before the forming process. Such blank can have the right properties located precisely where they are needed, minimizing the use of materials and reducing the weight and cost [1] [2]. Laser welding currently used to assemble this new kind of blank performs very well than other welding methods in terms of speed, cost, and welding quality. In automotive bodies, no other process has shown an equivalent versatility with steel grades developed to meet the specific requirements of these applications.

The welding of thin steel sheets is mainly done with overlap welding or buttjoint welding. Galvanized sheets are used for corrosion prevention, but the zinc vaporizes at a lower temperature $(1180 \mathrm{~K})$ than that at which the steel fuses $(1730 \mathrm{~K})$. Due to this discrepancy, problems occur during overlap laser welding of galvanized sheets: vaporization of the zinc might displace liquid steel, and vapour can get trapped in the weld and create porosities [3] [4]. Several studies have dealt with this problem by creating a gap between sheets to enable off-gassing of the vapour without disturbing the weld pool, or by adjusting other parameters to reduce the size and the number of defects [5] [6].

Butt-joint welding is commonly used to avoid these kinds of problems, but this configuration requires very precise positioning. A vertical gap of only $15 \%$ of the thickness and a horizontal gap of $10 \%$ of the thickness can be tolerated to ensure quality and filling of the weld. For sheets thinner than $3 \mathrm{~mm}$, this means less than a $0.5 \mathrm{~mm}$ gap on along more than $10 \mathrm{~cm}$ of weld. Since laser welding is an autogenous process, the residual stress developed during cooling is used to fill the gap up to at least $80 \%$ of the thickness, which is generally required in the automotive industry. Another requirement is that the laser diameter (about 0.4 $\mathrm{mm}$ ) be two times larger than the gap to avoid defects. To reach positioning requirements, laser cutting, precision die blanking, or edge preparation are commonly used for linear welding [7]. To avoid the filling problem in butt-joint configurations, filler metal in the form of wire or powder can be used in conjunction with laser welding. Such methods can fill up to $1 \mathrm{~mm}$ gaps for $2 \mathrm{~mm}$ thickness sheets, but reduce the advantage of the laser welding process [8].

Neural networks have been used to determine the maximum gap that can be welded depending on the welding speed, the laser power and the sheet thickness [9]. Another study has been conducted on the impact of the gap and edge roughness on penetration for high power laser welding (10 kW to $14 \mathrm{~kW}$ ) [10]. Effects on depth of penetration and others welds quality are established for various welding parameters. Works on welding parameters optimization for tailor blank welding reveal that the use of a small gap between $0.1 \mathrm{~mm}$ and $0.15 \mathrm{~mm}$ gives a relatively accepted welds quality [11] [12]. Many experimental others investigations find the use of a small gap can produce a best weld. But no relationships can be found to quantify the gap impact on the weld dimension, nor its interaction with the other welding parameters. 
Based on all these works and observations, it is clear that positioning and welding parameters need to be controlled precisely to produce the desired welding quality especially in the case of butt-joint welding of automotive bodies and tailor blank. A structured experimental investigation is required to understand the effects and the interaction of various parameters in orders to build an efficient weld quality predictive modeling.

The paper presents an experimental investigation of laser welding low carbon galvanized steel in butt-joint configurations. The effects of welding parameters and conditions (laser power, welding speed, laser fiber diameter, gap between sheets and sheet thickness) on the variation of weld quality attributes (bead width, penetration depth, underfill and hardness) are studied. Analysis of variance is executed to quantify the impact of each parameter on the welds quality and assess the parameters interactions. The combination of welding parameters and conditions that can give the best welds quality for various thickness with or without gap are identified.

\section{Materials and Experimental Procedure}

\subsection{Materials}

The experimental investigations were conducted using galvanized steel ASTM A635CS with galvanneal A40 coating. The sheet thickness was chosen to fit within the thickness range usually used for automotive bodies $(0.8-3.6 \mathrm{~mm})$. Three different thicknesses are taken: gauges 11,14 and 20, respectively $3.132 \mathrm{~mm}$, $1.994 \mathrm{~mm}$ and $1.006 \mathrm{~mm}$. The chemical compositions of all sheets are shown in Table 1. Specimens were cut to $30 \mathrm{~mm} \times 50 \mathrm{~mm}$ using hydraulic shear. The edge did not receive further treatment. The small differences in chemical composition are neglected.

\subsection{Laser Experimental Procedure}

The welding equipment was a six-axis-robotic system FANUC M-710ic equipped with a fiber Laser source IPG YLS-3000-ST2 and a laser head HIGHYAG BIMO. The Nd:YAG laser source emits light with a wavelength of $1070 \mathrm{~nm}$ and a maximum power of $3 \mathrm{~kW}$. The power is transferred through an optical fiber, with a diameter of $200 \mu \mathrm{m}$, to the laser head, with a focal length of $300 \mathrm{~mm}$. A collimator allows the user to adjust the beam diameter between $340 \mu \mathrm{m}$ and 520 $\mu \mathrm{m}$. Figure 1 shows the laser welding setup with the laser and the clamping

Table 1. Chemical composition of the metal.

\begin{tabular}{cccccccccccc}
\hline Component & $\mathrm{C}$ & $\mathrm{Mn}$ & $\mathrm{P}$ & $\mathrm{S}$ & $\mathrm{Si}$ & $\mathrm{Cu}$ & $\mathrm{Ni}$ & $\mathrm{Cr}$ & $\mathrm{Al}$ & $\mathrm{N}$ \\
\hline $\begin{array}{c}\text { Gauge } 11 \\
(3 \mathrm{~mm})\end{array}$ & 0.04 & 0.19 & 0.005 & 0.002 & 0.01 & 0.01 & 0.02 & 0.009 & 0.038 & 0.0039 \\
$\begin{array}{c}\text { Gauge } 14 \\
(2 \mathrm{~mm})\end{array}$ & 0.09 & 0.35 & 0.005 & 0.01 & 0.02 & 0.05 & 0.04 & 0.06 & 0.03 & 0.0029 \\
$\begin{array}{c}\text { Gauge 20 } \\
(1 \mathrm{~mm})\end{array}$ & 0.05 & 0.24 & 0.009 & 0.013 & 0.007 & 0.029 & 0.012 & 0.037 & 0.04 & 0.004
\end{tabular}




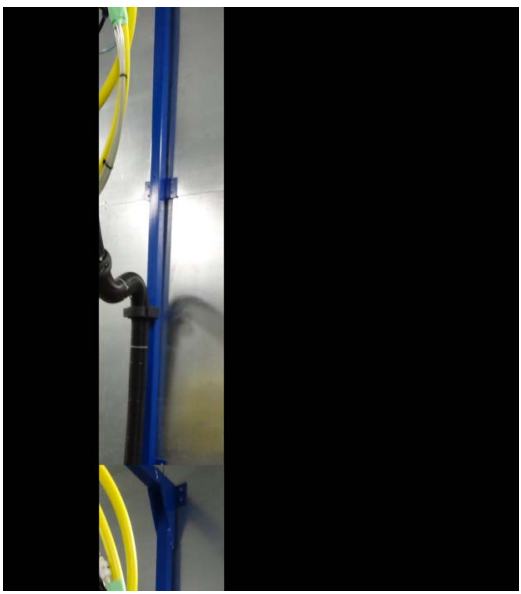

(a)

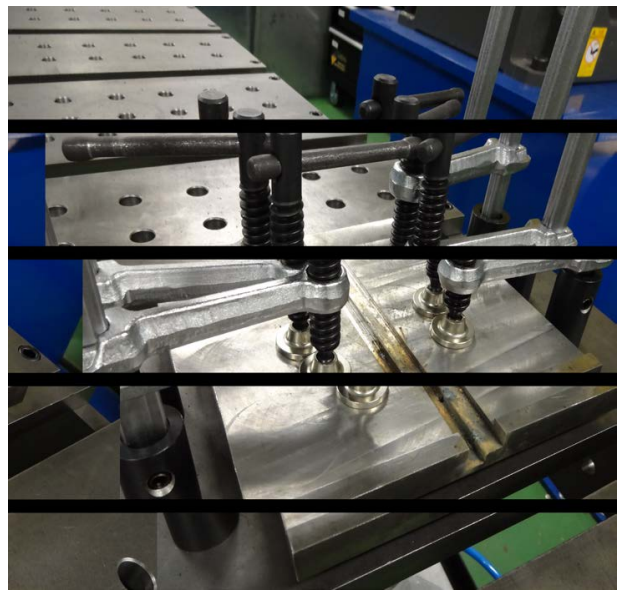

(b)

Figure 1. Experimental set-up showing (a) laser and (b) clamping system.

system. The air gap was created using a $0.1 \mathrm{~mm}$ thick steel strip positioned between the samples.

\subsection{Mechanical Characterization}

After welding, the welded assemblies were cut perpendicular to the weld surface to obtain the desired cross-sections. The cut specimens were then prepared for microscopic observation using standard procedures including grinding, polishing, and etching.

An optical microscope, Clemex MMT Type A, with a CMT program was used for the evaluation of the weld dimensions. For each experiment, three dimensions were measured (penetration, width, and lack); each measurement was taken 3 times and then averaged to obtain the data used in the analysis.

Vickers micro-hardness testing was conducted with the same equipment using a load of $500 \mathrm{~g}$ and a dwell time of $15 \mathrm{~s}$. The base material measurements were taken far from the fusion zone. All indentations were adequately spaced so that the strain fields from adjacent indents would not interfere with each other.

\subsection{Design of Experiments}

Laser power, welding speed, sheet thickness, beam diameter, and gap are the parameters used in this study. The thickness and laser beam diameter are chosen to fit with the available ranges: $1 \mathrm{~mm}, 2 \mathrm{~mm}$ and $3 \mathrm{~mm}$ for the thickness and 340 $\mu \mathrm{m}$ to $520 \mu \mathrm{m}$ for the diameter. The results of preliminary studies on the parameters limitations and the results of others similar studies [13], were used to determine upper and lower limits for the parameters.

For the gap, three relevant information emerged from the literature review. The gap has to be less than $10 \%$ of the workpiece thickness and less than the diameter of the laser beam. A gap ranging from $0.1 \mathrm{~mm}$ to $0.2 \mathrm{~mm}$ is generally used and gives good results. Considering these constraints, a gap of $0.1 \mathrm{~mm}$ is needed, leaving only the welding speed and laser power to be determined. These two parameters are known to be very influential. Using the results of the pre- 
liminary tests, the upper and lower limits are taken to respect the weld penetration constraint. This means that the lowest speed with the highest power can result in full weld penetration for a $3 \mathrm{~mm}$ thickness specimen, and the highest speed with lowest power can result in partial weld for a $1 \mathrm{~mm}$ thickness specimen. Three levels are chosen to assess the nonlinear components of the parameter effects: speed between 3 and $9 \mathrm{~m} / \mathrm{min}$, and power between 2 and $3 \mathrm{~kW}$. The factors and levels chosen can be seen in Table 2 .

These factors and levels are used to generate an experiment design that will yield the maximum data with the minimum experimentation efforts. The Taguchi method is used to achieve an efficient statistical analysis. An explanation of this method can be found in [14]. An orthogonal array L54 is used allowing the combination of factors with 2 or 3 levels. In this case one factor with 2 levels and four factors with 3 levels are needed. Welding tests are carried out in a random order to avoid any systematic error in the experiment. In addition, repeatability tests are done using the median values from the experiment design (2500 $\mathrm{W}$ power, $2 \mathrm{~mm}$ thickness, $6 \mathrm{~m} / \mathrm{min}$ speed and $450 \mu \mathrm{m}$ diameter). Since the positioning of the gap experiment requires different handling, 12 repeatability tests are done with a gap and 12 without gap, for a total of 24 supplementary tests.

\section{Results and Discussion}

\subsection{Repeatability}

During the repeatability tests, the depth of penetration, bead width, and underfill are precisely measured. In order to evaluate the total measurement error resulting from non-studied parameters such as workpiece positioning, parameter stability and change in environment during the experiments, average of quality attributes, standard deviations, and the relative errors are estimated.

The results in Table 3 indicated the good precision for the measurement of the penetration and the width, showing that with a normal distribution, $68 \%$ of observations will be within one standard deviation and 95\% will be within two standard deviations. This means that the penetration and the width can be estimated with less than $5 \%$ error and the underfilling can be estimated with less than $15 \%$ error. The underfill dimensions are relatively small generating higher error percentages. The standard deviations are similar for all parameters. The

Table 2. Factors and levels for experimentations.

\begin{tabular}{cccc}
\hline Factors & \multicolumn{3}{c}{ Levels } \\
\cline { 2 - 4 } & 1 & 2 & 3 \\
\hline Gap $(\mathrm{mm})$ & 0 & 0.1 & - \\
Thickness $(\mathrm{mm})$ & 1 & 2 & 3 \\
Power $(\mathrm{kW})$ & 2 & 2.5 & 9 \\
Speed $(\mathrm{m} / \mathrm{min})$ & 3 & 6 & 520 \\
Diameter $(\mu \mathrm{m})$ & 340 & 450 &
\end{tabular}


Table 3. Results of repeatability test (a) no gap and (b) with gap.

\begin{tabular}{cccccccc}
\hline (a) no gap & $\begin{array}{c}\text { DOP } \\
(\mu \mathrm{m})\end{array}$ & $\begin{array}{c}\text { BDW } \\
(\mu \mathrm{m})\end{array}$ & $\begin{array}{c}\text { Undercut } \\
(\mu \mathrm{m})\end{array}$ & $\begin{array}{c}(\mathrm{b}) \text { with gap } \\
(\mu \mathrm{m})\end{array}$ & $\begin{array}{c}\text { BDW } \\
(\mu \mathrm{m})\end{array}$ & $\begin{array}{c}\text { Undercut } \\
(\mu \mathrm{m})\end{array}$ \\
\hline Min & 1493 & 971 & 154 & Min & 1167 & 713 & 360 \\
Max & 1612 & 1080 & 254 & Max & 1353 & 922 & 507 \\
Mean & 1542 & 1023 & 212 & Mean & 1253 & 822 & 422 \\
$\begin{array}{c}\text { Standard } \\
\text { deviation }\end{array}$ & 38 & 32 & 30 & $\begin{array}{c}\text { Standard } \\
\text { deviation }\end{array}$ & 43 & 42 & 39 \\
Relative error & $2 \%$ & $3 \%$ & $12 \%$ & Relative error & $3 \%$ & $3 \%$ & $7 \%$ \\
\hline
\end{tabular}

standard deviation is slightly higher for the gap test. That means there is lower repeatability in the gap positioning.

An underfill of $10 \%$ of the thickness is present in the case of experimentation without gap. This must be caused by the edge morphology of the sheared edge. Flat or concave welds are produced using laser cutting or precision die blanking. A small gap exists when two sheared specimens are connected, as only the 2 burnished zone are in contact, the rest of the edge are spaced. The underfilling becomes about $20 \%$ of the thickness with the gap experiment. Figure 2 shows the morphology of the edge of the specimen used for the experiment. The dimensions of the sheared edge have been measured and are relatively close for the $3 \mathrm{~mm}$ thickness. The rollover accounts for about $10 \%$ of the thickness, the burnished zone between $40 \%$ and $45 \%$, and the fractured zone for $50 \%$. The fracture angle ranges from $12^{\circ}$ to $15^{\circ}$.

\subsection{Micro Hardness}

Figure 3 shows the distribution of micro-hardness across the laser welding zone for the repeatability test. According to the hardness test, the hardness of the substrate $(150 \mathrm{Hv})$ was much lower than that of the welded region $(330 \mathrm{Hv})$, which agreed with the results found for low carbon steel [8]. The increase in hardness is caused by grain refinement, formation of hard phases and generation of residual stress in the weld region due to rapid solidification [11]. The microhardness is comparable in all tests, with and without gap.

\subsection{Taguchi}

To obtain the effects of each factor on the weld dimensions, ANOVA were carried out based on the measured results as illustrated in Table 4 and Table 5. The $\mathrm{p}$ value is used to determine if the factor has an impact on a given parameter, and the percentage represents the risk of concluding that an influence exists when there is no actual influence. The percentage contribution is the variation caused by an individual factor over the total variation.

Any factor whose $\mathrm{p}$-value is under $10 \%$ will be considered meaningful. According to the results for the BDW, every factor is found to be meaningful. The gap is the least meaningful factor, with a p-value of $7 \%$. For the DOP, the range of variation in diameter is found to not be an impacting factor, while all the 


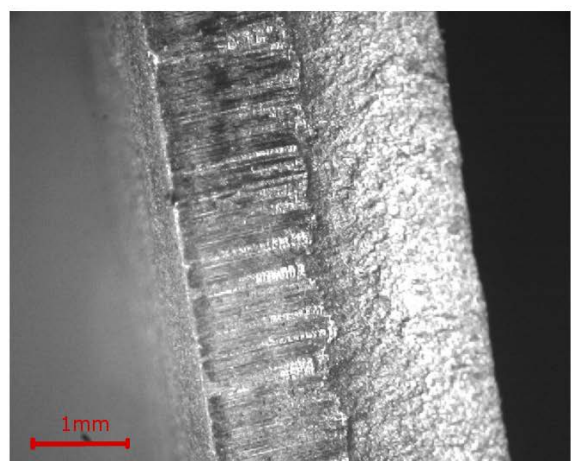

(a)

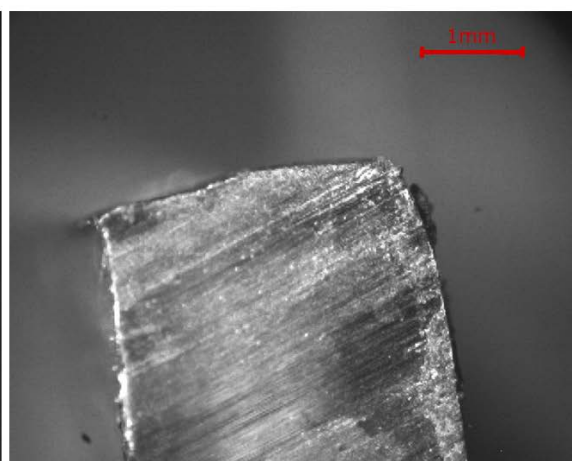

(b)

Figure 2. Sheared edge specimens (a) front view, (b) side view.

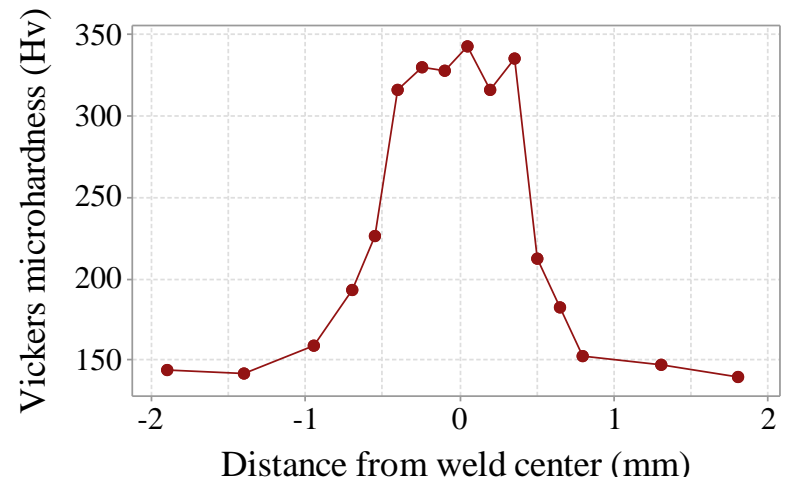

Figure 3. Micro hardness profile of the welded joint.

Table 4. ANOVA table for BDW.

\begin{tabular}{ccccccc}
\hline Source & $\begin{array}{c}\text { Sum of } \\
\text { squares }\end{array}$ & dof & $\begin{array}{c}\text { Mean } \\
\text { square }\end{array}$ & F value & $\begin{array}{c}\text { p value } \\
\text { Prob > F }\end{array}$ & $\begin{array}{c}\text { Percent } \\
\text { contribution }\end{array}$ \\
\hline Gap & 57,537 & 1 & 57,537 & 8.07 & $7 \%$ & $2 \%$ \\
Thickness & 53,538 & 2 & 26,769 & 3.76 & $3 \%$ & $2 \%$ \\
Power & 65,022 & 2 & 32,511 & 4.56 & $0 \%$ & $2 \%$ \\
Diameter & 237,072 & 2 & 118,536 & 16.63 & $0 \%$ & $13 \%$ \\
Speed & $1,336,393$ & 2 & 668,197 & 93.74 & - & $18 \%$ \\
Error & 313,653 & 44 & 7128 & - & - & $100 \%$ \\
Total & $2,313,027$ & 53 & - & - & & \\
\hline
\end{tabular}

Table 5. ANOVA table for DOP.

\begin{tabular}{ccccccc}
\hline Source & $\begin{array}{c}\text { Sum of } \\
\text { squares }\end{array}$ & dof & $\begin{array}{c}\text { Mean } \\
\text { square }\end{array}$ & F value & $\begin{array}{c}\text { p value } \\
\text { Prob > F }\end{array}$ & $\begin{array}{c}\text { Percent } \\
\text { contribution }\end{array}$ \\
\hline Gap & 227,587 & 1 & 227,587 & 3.32 & $8 \%$ & $2 \%$ \\
Thickness & $4,009,900$ & 2 & $2,004,950$ & 29.26 & $0 \%$ & $39 \%$ \\
Power & 922,458 & 2 & 461,229 & 6.73 & $0 \%$ & $8 \%$ \\
Diameter & 239,568 & 2 & 119,784 & 1.75 & $19 \%$ & $1 \%$ \\
Speed & $2,522,684$ & 2 & $1,261,342$ & 18.41 & $0 \%$ & $24 \%$ \\
Error & $2,014,932$ & 44 & 45,794 & - & - & $24 \%$ \\
Total & $9,937,129$ & 53 & - & - & - & $100 \%$ \\
\hline
\end{tabular}


other factors are meaningful. The percentage contribution for the BDW attributes $18 \%$ of variation to non-studied factors, with the two main factors being speed $(63 \%)$ and diameter (13\%). The major factors for the DOP are speed $(24 \%)$ and thickness (39\%), while non-studied factors represent $24 \%$ of variation.

\subsection{Effect and Interaction}

Figure 4 shows the effects of each of the 5 factors. The direction and steepness of the slope are used to determine the impact. We can see that the use of a gap reduces the width and increases the penetration. The diameter, contrary to the gap, increases the width and reduces the penetration. Thickness and power have a positive impact on the width and the penetration, while speed has the opposite impact, reducing the penetration and the width. Every line is roughly straight, so the effect of the parameter does not change as it increases. The speed seems to have a stronger effect because it has a wide range of variation. In conclusion, three factors have a similar impact on penetration and width, while two factors have the opposite. The results for power, diameter and speed fit with [15].

To visualize whether the effect of one factor depends on the level of another factor, we used an interaction plot. Parallel lines in an interaction plot indicate no interaction; otherwise, the greater the difference in slope between the lines, the higher the degree of interaction. Only one significant difference in slope is found for the BDW. As can be seen in Figure 5, the thickness tends to increase the width without gap, but when using gap, thickness variation has insignificant impact on the bead width. This means that the weld done using a gap would stay thinner for thicknesses greater than $1 \mathrm{~mm}$.
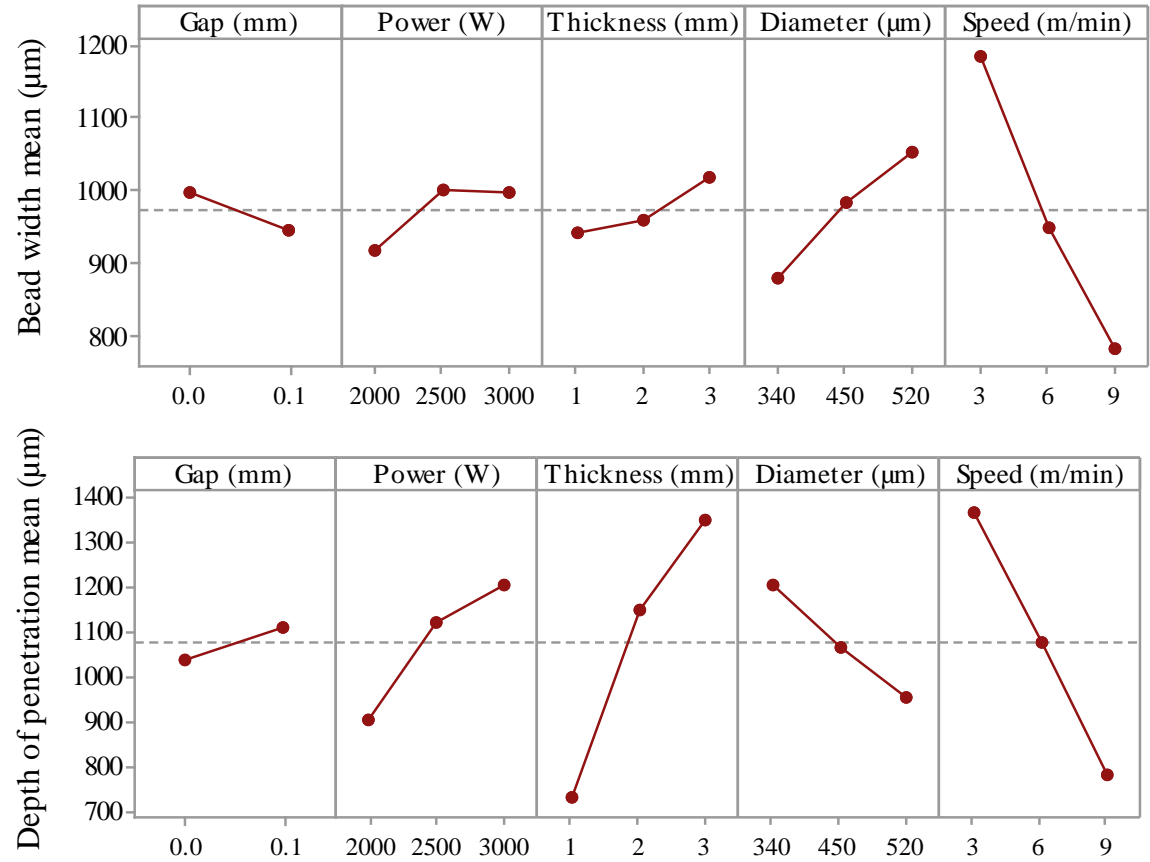

Figure 4. Main effect plot for BDW and DOP. 
Interaction seems to be found between the thickness and the other factors for the DOP. Figure 6 shows the graph for speed and thickness. The interaction found is that using a greater thickness, with the values of the other factors giving the best penetration, allows a deeper weld, which is a logical interaction. For example, welding a $1 \mathrm{~mm}$ thickness sheet at low speed gives a full penetration weld that is about $1 \mathrm{~mm}$, but using a $3 \mathrm{~mm}$ sheet gives a $3 \mathrm{~mm}$ weld, and when welding at a high speed both thicknesses have the same low penetration. This explains the change in the slope steepness, and is the same for all of the factors.

\subsection{Weld Shape}

The shape of the weld is mainly determined by the welding mode conduction or keyhole. As we can see in Assuncao study [16] [17], there is not a sharp transition between conduction mode and keyhole mode. The mode is dependent on the interaction time and power density. In our experiments the interaction time varies between $2 \mathrm{~ms}$ and $10 \mathrm{~ms}$, and the power density between $0.95 \mathrm{MW} / \mathrm{cm}^{2}$ and $3.3 \mathrm{MW} / \mathrm{cm}^{2}$. Given those values, the experiment's range must be in the transition mode and the keyhole mode. The results give an aspect ratio between 0.5 and 2.2, which fits with these modes.

The weld shape is supposed to be from small and round to thin and deep, which is what we observe. Four weld shapes are considered: 1) round welds are

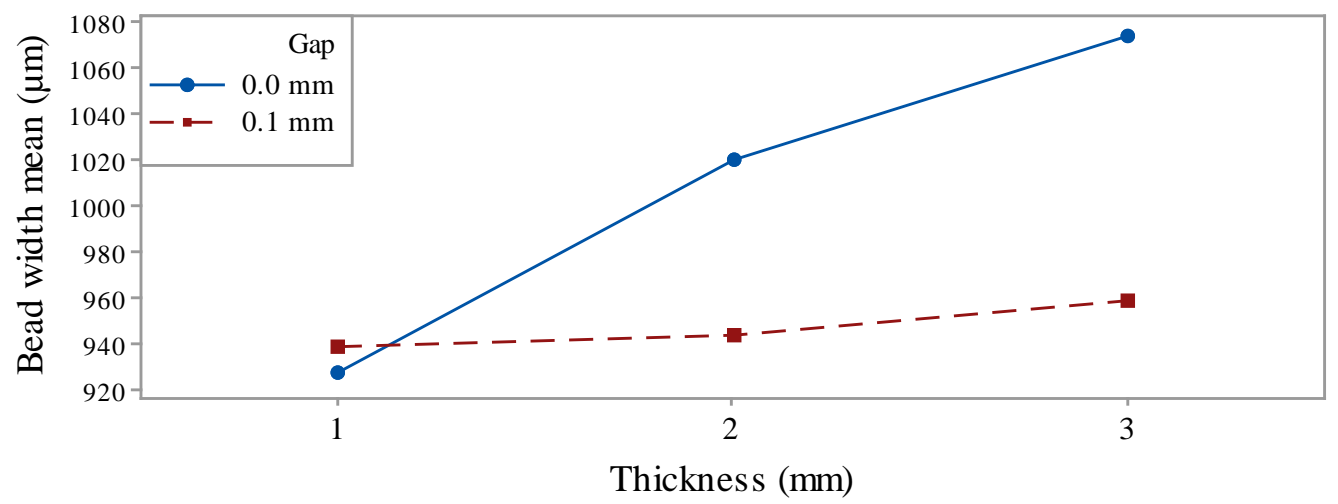

Figure 5. Interaction plot between thickness and gap for BDW.

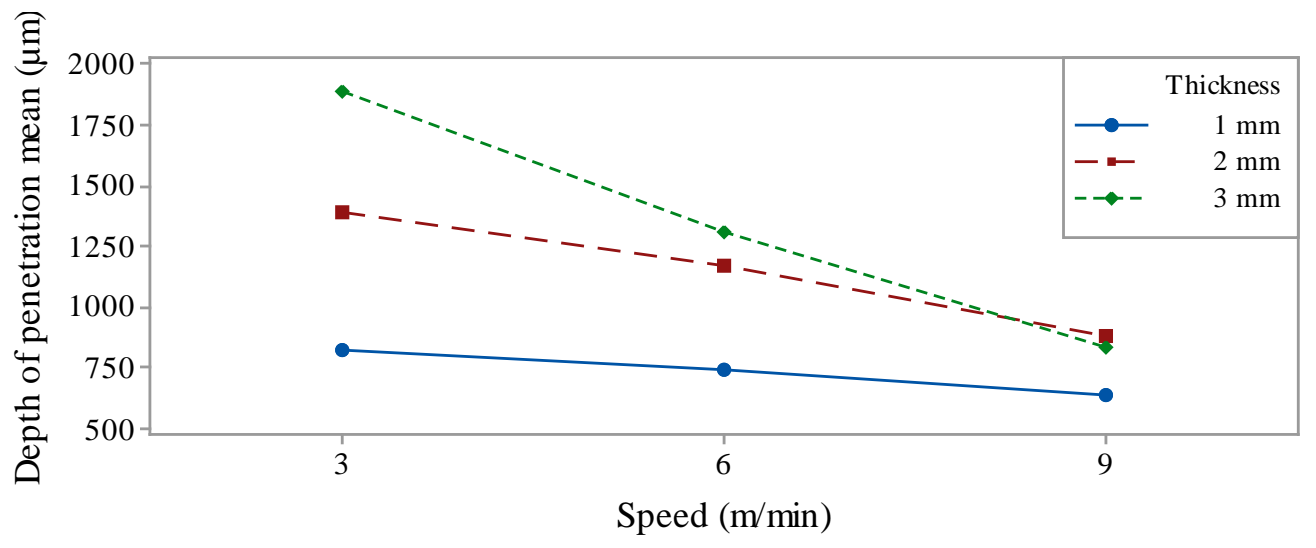

Figure 6. Interaction plot between speed and thickness for DOP. 
the welds almost in conduction mode (U weld), 2) wide $\mathrm{V}$ welds are the welds in transition mode (HV weld), 3) sharp V welds are those between transition mode and keyhole mode 4) weld), and 5) parallel edge welds are those with full penetration done in keyhole mode ( $\mathrm{H}$ weld). Figure 7 gives a picture for each of the four morphologies.

Figure 8 represents the weld shape according to the DOP, the gap and the thickness. We notice that the round and wide $\mathrm{V}$ welds are only found in experiments without gap. The shape depends on the penetration of the weld, with the lowest penetration weld being round shaped, then wide $\mathrm{V}$ shaped, then sharp $\mathrm{V}$ shaped and finally parallel edge with the no-gap experiments. This order can be found for all three thicknesses. The penetration is directly linked to power density and interaction time. The experiments with gap only produce sharp $\mathrm{V}$ shaped welds for partial welds, and mainly parallel edge welds for full penetration. However, sometimes there can be a V shaped full penetration weld, which does not appear without gap.
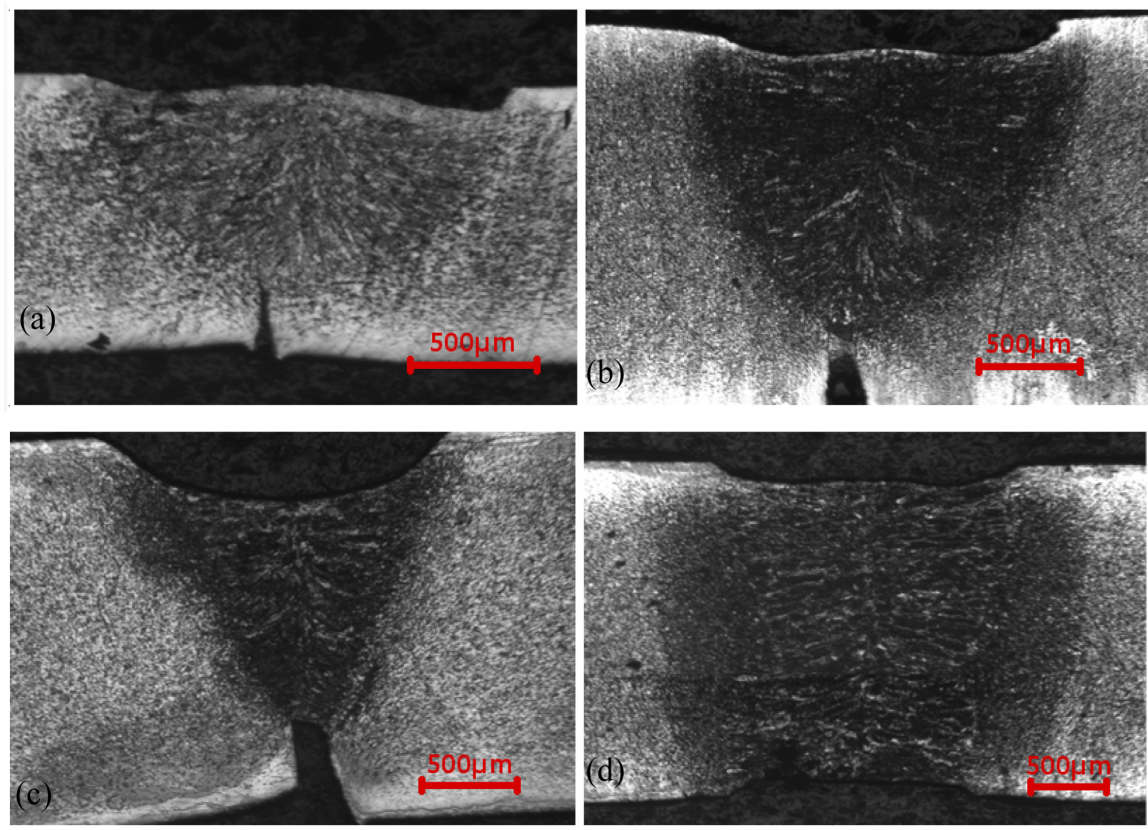

Figure 7. Shape of the weld (a) round shape, (b) wide V shape, (c) sharp V shape, (d) parallel edge.

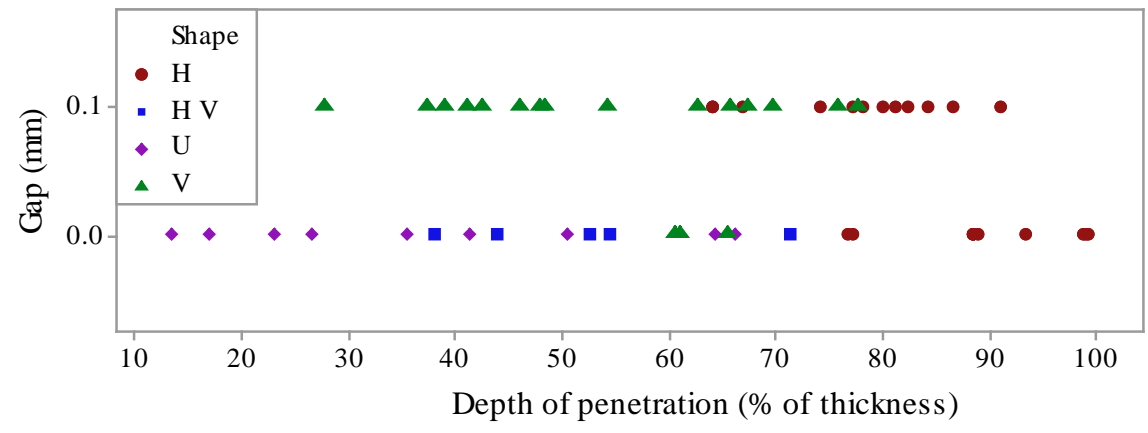

Figure 8. Weld shape according to the DOP, the gap and the thickness. 
The use of a gap tends to make only sharp V shaped welds in the case of partial penetration welds. The assumption can be made that the gap allows an easier penetration for the weld because the melted metal can flow into the gap. The deepest penetrations achieved with gap are deeper than penetrations without gap because of this easier penetration. The higher penetrations achieved with gap are shallower than those without gap, because there is more underfilling caused by the gap. We can also remark that all sharp $\mathrm{V}$ welds without gap have more than $50 \%$ penetration, which is where the burnished zone and the fracture zone begin forming an unintended gap between the pieces.

\subsection{Underfill}

The experimental results reveal that tests with gap have more underfill than those with no gap. Figure 9 presents the distribution of the underfill versus the DOP in \% of specimens' thickness. Excluding the alignment on the right, the figure reveals the presence of an underfill of about $5 \%$ for the experiments without gap. The underfill tends to grow slightly after $50 \%$ penetration. This is certainly due to the fracture zone. An underfill between $10 \%$ and $15 \%$ is present when using gap. When looking at the alignment on the right, a trend appears with depth of penetration plus underfill equal 100\%. Furthermore, the points on that line were for full penetration welds. Only the underfill on the upper face has been measured. That is why when underfill exists on the bottom face, the sums are slightly less than $100 \%$. This suggests the question why all the full penetration welds do not have the same underfill.

Figure 10 presents the BDW versus the underfill for full penetration weld. This figure shows that the width decreases when the underfill increases. This observation fits with the refillable gap formula: $g=A^{\star} B^{\star} \Delta T^{*} W$ proposed in [18], where $A$ is constant, $B$ is the coefficient of thermal dilatation, $\Delta T$ is the temperature differential, and $\mathrm{w}$ is the width. The measurements in the bottom right corner reveal the weld with the least underfill. The use of gap moves this point upward by about $10 \%$, but maintains the same slope, and the underfill is substantially greater for the same width. This means that when using a gap the underfill is bigger for the same bead width. The largest number of full penetration welds are achieved using $1 \mathrm{~mm}$ sheet thickness explains the larger number point

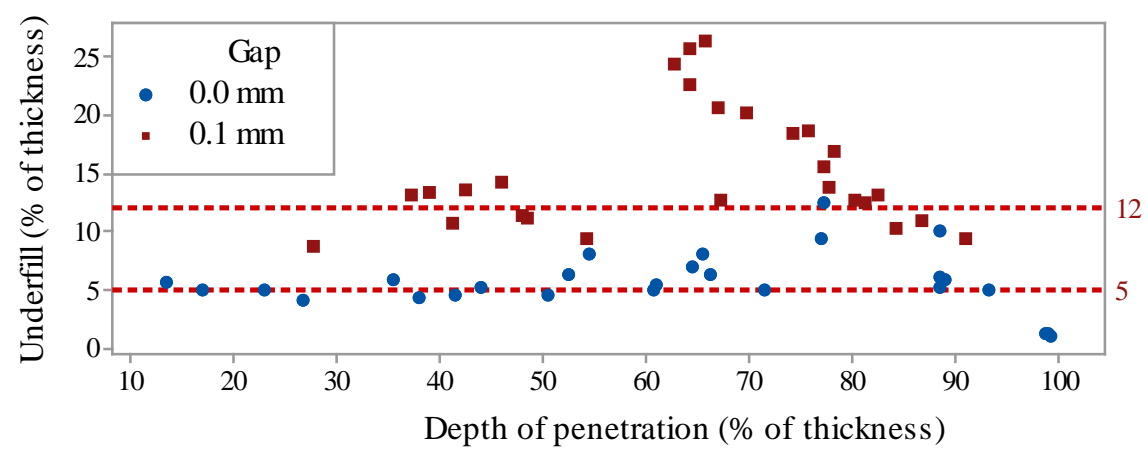

Figure 9. Shape of the weld according to the DOP, the gap and the thickness. 


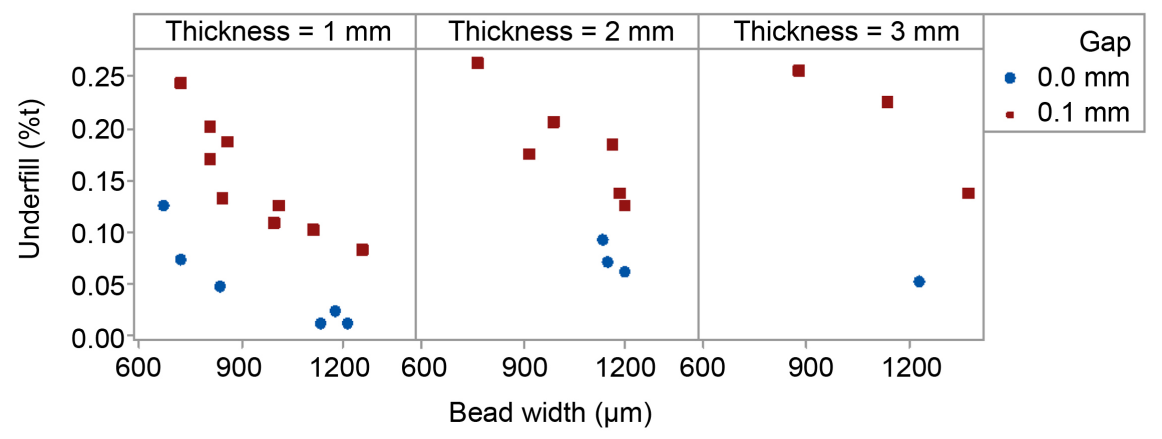

Figure 10. Shape of the weld according to the DOP, the gap and the thickness.

in the graph. The underfill also increases slightly with the thickness because of the sheared edge that creates more gap with increased thickness. In order to achieve good weld on thicker plate, wider weld have to be done if there's no additional edge preparation.

\section{Conclusion}

This paper presents an experimental investigation of laser welding low carbon galvanized steel in butt-joint configurations. The experimental work is focused on bead width, penetration depth, underfill and hardness using various laser welding parameters such as laser power, welding speed, laser fiber diameter, gap between sheets and sheet thickness. There are 54 experimental tests taken all factors known to have an influence on welds quality to conduct a systematic study using Taguchi methods. ANOVA analysis and effect plot diagrams are also used to evaluate the effects and the percentage contribution of the laser welding parameters on the characteristics of the weld. The micro hardness measurements show coherent results with an increase in the weld hardness from $150 \mathrm{Hv}$ to 330 Hv. The ANOVA analysis reveals that the welding parameters that have significant effects on the weld quality are laser power, welding speed, laser fiber diameter and sheet thickness. The gap between sheets has a positive effect on the weld dimensions by making the weld thinner and deeper permitting the higher speeds for the same penetration. The use of a gap decreases the thickness effect on the bead width and facilitates the formation of $\mathrm{V}$ shaped welds. An underfill between $5 \%$ and $10 \%$ is observed for no-gap experiments and increases by about $10 \%$ when using gap. The sheared edges explain several observations on the underfill and the shape of the weld. Finally, the welding parameters that can give the best welds quality for various thickness with or without gap are identified.

\section{References}

[1] Ribolla, A., Damoulis, G.L. and Batalha, G.F. (2005) The Use of nd:Yag Laser Weld for Large Scale Volume Assembly of Automotive Body in White. Journal of Materials Processing Technology, 164-165, 1120-1127. https://doi.org/10.1016/j.jmatprotec.2005.02.104

[2] Mei, L., Yan, D., Chen, G., Xie, D., Zhang, M. and Ge, X. (2015) Comparative Study on $\mathrm{CO}_{2}$ Laser Overlap Welding and Resistance Spot Welding for Automotive Body 
in White. Materials \& Design, 78, 107-117.

https://doi.org/10.1016/j.matdes.2015.04.031

[3] Uchihara, M. (2011) Joining Technologies for Automotive Steel Sheets. Welding International, 25, 249-259. https://doi.org/10.1080/09507111003655341

[4] Schmidt, M., Otto, A. and Kägeler, C. (2008) Analysis of yag Laser Lap-Welding of Zinc Coated Steel Sheets. CIRP Annals-Manufacturing Technology, 57, 213-216. https://doi.org/10.1016/j.cirp.2008.03.043

[5] Zhao, Y., Zhang, Y., Hu, W. and Lai, X. (2012) Optimization of Laser Welding Thin-Gage Galvanized Steel via Response Surface Methodology. Optics and Lasers in Engineering, 50, 1267-1273. https://doi.org/10.1016/j.optlaseng.2012.03.010

[6] Amo, J.M., Durán, J., Chao, J. and Fernández-Sáez, J. (1996) Laser Welding of $\mathrm{Al}_{55}$-Zn Coated Steel Sheet. Journal of Materials Science, 31, 6595-6607. https://doi.org/10.1007/BF00356267

[7] Spöttl, M. and Mohrbacher, H. (2014) Laser-Based Manufacturing Concepts for Efficient Production of Tailor Welded Sheet Metals. Advances in Manufacturing, 2, 193-202. https://doi.org/10.1007/s40436-014-0088-8

[8] Sun, Z. and Kuo, M. (1999) Bridging the Joint Gap with Wire Feed Laser Welding. Journal of Materials Processing Technology, 87, 213-222. https://doi.org/10.1016/S0924-0136(98)00346-X

[9] Jeng, J.-Y., Mau, T.-F. and Leu, S.-M. (2000) Prediction of Laser Butt Joint Welding Parameters Using Back Propagation and Learning Vector Quantization Networks. Journal of Materials Processing Technology, 99, 207-218. https://doi.org/10.1016/S0924-0136(99)00424-0

[10] Sokolov, M. and Salminen, A. (2012) Experimental Investigation of the Influence of Edge Morphology in High Power Fiber Laser Welding. Physics Procedia, 39, 33-42. https://doi.org/10.1016/j.phpro.2012.10.011

[11] Suh, J., Kim, T., Yu, B. and Lee, K. (1998) A Study of Tailored Blank Welding between Mild Steel Sheet and Zn-Coated Steel Sheet by $\mathrm{CO}_{2}$ Laser Beam. Metals and Materials, 4, 157-163. https://doi.org/10.1007/BF03026033

[12] Park, J. and Kim, T. (1999) Tailored Blank Welding between Low Carbon Steel Sheet and STS 304 Stainless Steel Sheet by $\mathrm{CO}_{2}$ Laser Beam. Metals and Materials, 5, 55-62. https://doi.org/10.1007/BF03026005

[13] America, L.I., Ready, J.F. and Farson, D.F. (2001) Lia Handbook of Laser Materials Processing. Laser Institute of America, Magnolia Publishing, Orlando.

[14] Ross, P.J. (1996) Taguchi Techniques for Quality Engineering: Loss Function, Orthogonal Experiments, Parameter and Tolerance Design. McGraw-Hill, New York.

[15] Khan, M.M.A., Romoli, L., Fiaschi, M., Sarri, F. and Dini, G. (2010) Experimental Investigation on Laser Beam Welding of Martensitic Stainless Steels in a Constrained Overlap Joint Configuration. Journal of Materials Processing Technology, 210, 1340-1353. https://doi.org/10.1016/j.jmatprotec.2010.03.024

[16] Assuncao, E., Williams, S. and Yapp, D. (2012) Interaction Time and Beam Diameter Effects on the Conduction Mode Limit. Optics and Lasers in Engineering, 50, 823-828. https://doi.org/10.1016/j.optlaseng.2012.02.001

[17] Assuncao, E. and Williams, S. (2013) Comparison of Continuous Wave and Pulsed Wave Laser Welding Effects. Optics and Lasers in Engineering, 51, 674-680. https://doi.org/10.1016/j.optlaseng.2013.01.007

[18] Steen, W.M. and Mazumder, J. (2010) Laser Material Processing. Springer, London. https://doi.org/10.1007/978-1-84996-062-5 
Submit or recommend next manuscript to SCIRP and we will provide best service for you:

Accepting pre-submission inquiries through Email, Facebook, LinkedIn, Twitter, etc. A wide selection of journals (inclusive of 9 subjects, more than 200 journals)

Providing 24-hour high-quality service

User-friendly online submission system

Fair and swift peer-review system

Efficient typesetting and proofreading procedure

Display of the result of downloads and visits, as well as the number of cited articles Maximum dissemination of your research work

Submit your manuscript at: http://papersubmission.scirp.org/

Or contact wjet@scirp.org 